\title{
PERANCANGAN DAN PEMBUATAN TEKNOLOGI AUGMENTED REALITY SEBAGAI MEDIA PEMBELAJARAN AKSARA MINANG DI SDN 01 PATAMUAN BERBASIS ANDROID
}

\author{
Andre Irawan ${ }^{1}$, Randy Permana, S.Kom, M.Kom ${ }^{2}$, Muhammad Reza Putra, \\ S.Kom, M.Kom ${ }^{3}$ \\ Universitas Putra Indonesia YPTK,Padang, Indonesia \\ e-mail: andreirawan99@gmail.com ${ }^{1)}$, randydoank17@gmail.com ${ }^{2}$, muhammad_reza@upiyptk.ac.id ${ }^{3}$
}

\begin{abstract}
ABSTRAK
Augmented reality merupakan sebuah teknologi yang dapat menggabungkan antara dunia nyata dengan dunia virtual. Seiiring berjalannya waktu augmented reality dikembangkan pada berbagai bidang contoh nya yaitu bidang pendidikan. Aksara minang merupakan sebuah kebudayaan tulisan yang berasal dari alam minangkabau yang ditemukan pada kitab tambo alam. Aksara minang sendiri terdapat 15 buah huruf aksara dan lima tanda untuk tanda baca. Dengan memanfaatkan teknologi augmented reality ini dapat menjadikan sebuah pembelajaran mengenai aksara minang
\end{abstract}

Kata kunci: Bahasa Jepang, Augmented Reality, Vuforia, Unity3d, C\#

\section{Pendahuluan}

Perkembangan teknologi informasi dan komunikasi pada saat ini sangat berkembang dengan pesat. Hal ini ditandai dengan adanya teknologi augmented reality. Augmented reality atau yang disingkat AR adalah teknologi yang menggabungkan dunia nyata dengan dunia virtual (Azuma, 1997). AR dapat dijalankan di perangkat smartphone yang berbasis sistem operasi android.

Ada banyak cara untuk mengembangkan augmented reality misalnya ARToolkit, Flartoolkit, Goblin, dan lain sebagainya. Augmented reality membutuhkan kamera smartphone yang digunakan untuk melacak marker (penanda) dan setelah marker terdeteksi maka akan muncul objek 3D atau informasi lainnya.

Seiring berjalannya waktu augmented reality dapat dikembangkan di berbagai bidang termasuk bidang pendidikan. Pada kesempatan kali ini penulis ingin mengembangkan augmented reality untuk media pembelajaran aksara minang. Yang mana pada saat sekarang ini masyarakat minang banyak yang tidak mengenal bagaimana bentuk penulisan aksara minang tersebut.

Aksara minang ditemukan dalam kitab Tambo Alam milik Datuk Suri Dirajo dan Datuk Bandaro Kayo di Pariangan, Padang Panjang. Kitab Tambo Alam tersebut ditulis dalam tulisan aksara minang yang mana didalamnya terdapat undang-undang adat. Aksara minang terdiri dari 15 buah huruf aksara dan lima tanda untuk tanda baca.

Dengan memanfaatkan teknologi augmented reality pada aplikasi pembelajaran aksara minang ini, nantinya para siswa akan mendapatkan informasi mengenai tanda baca dan juga arti dari aksara minang tersebut. Diharapkan dengan adanya teknologi augmented reality ini dapat menarik minat dan mempermudah pembelajaran mengenai huruf aksara minang di SDN 01 Patamuan. Berdasarkan permasalahan tersebut maka penulis ingin membuat penelitian dengan judul "PERANCANGAN DAN PEMBUATAN TEKNOLOGI AUGMENTED REALITY SEBAGAI MEDIA PEMBELAJARAN AKSARA MINANG DI SDN 01 PATAMUAN BERBASIS ANDROID" 


\section{Tinjauan Literatur}

\subsection{Sistem Operasi Android}

Android adalah sistem operasi bergerak (mobile operating system) yang mengadopsi sistem operasi linux, namun telah dimodifikasi. Pada tahun 2005 Android,Inc diambil alih oleh google yaitu dengan mengambil alir seluruh hasil kerja android termasuk tim yang mengembangkan android. Keuntungan utama dari android adalah adanya pendekatan aplikasi secara terpadu. Pengembang hanya berkonsentrasi pada aplikasi saja, aplikasi tersebut bisa berjalan pada beberapa perangkat yang berbeda beda selama masih ditenagai oleh android (Sigit, Haris Triono, dan Sulistiyono, 2017).

\subsection{Augmented Reality}

Menurut Ronald T Azuma didalam buku Arifitama, Budi (2017) : “Augmented Reality adalah sebuah variasi dari Virtual Environment atau yang lebih dikenal sebagai Virtual Reality. Teknologi Augmented Reality dalam penggunaannya menempatkan pengguna ke dalam lingkup virtual sehingga pengguna merasakan sensasi masuk ke dalam lingkungan aplikasi”.

Selain digunakan didalam bidang kesehatan, militer, industri manufaktur, augmented reality dapat diaplikasikan pada bidang pendidikan seperti pengenalan hewan untuk anak usia dini. Dimana augmented reality ini dapat menampilkan animasi 3D hewan dan menampilkan informasi mengenai hewan tersebut. Sehingga augmented reality ini mempunyai daya tarik baru dalam bidang media pembelajaran, dan dirancang dengan konsep yang lebih berwarna dan interaktif yang akan memberikan suasana belajar baru bagi anak anak (Indriani, Riana, dkk, 2016).

\subsection{Unity $3 D$}

Unity $3 D$ merupakan sebuah platform pengembangan game 2 dimensi maupun 3 dimensi yang dapat digunakan oleh pengembang baru maupun yang dapat digunakan oleh pengembang yang sudah berpengalaman (Arifitama, Budi, 2017).

\subsection{Blender}

Menurut (Ardhianto, Eka, dkk, 2012) didalam jurnal nya menyatakan bahwa Blender adalah salah satu software open source yang digunakan untuk membuat konten multimedia khususnya 3 Dimensi. Ada beberapa kelebihan yang dimiliki blender yaitu :

a. Open Source

Blender merupakan salah satu software open source, dimana kita bisa bebas memodifikasi source codenya untuk pribadi maupun komersial asalkan tidak melanggar GNU (General Public License).

b. Multi Platform

Karena sifatnya open source, blender tersedia untuk berbagai macam sistem operasi seperti linux, mac, da windows.

c. Update

Dengan status nya open source blender bisa dikembangkan oleh siapapun, sehingga update software ini lebih cepat dibandingkan software yang lainnya.

d. Free

Blender merupakan sebuah software yang gratis yang bisa dipakai oleh siapapun.

e. Lengkap 
Blender memiliki fitur yang lebih lengkap dibandingkan oleh software 3D lainnya

f. Ringan

Blender lebih ringan dari software 3D lainnya. Hal ini terbukti dengan sistem minimal yang rendah untuk menjalankan blender.

\subsection{Vuforia SDK}

Dalam jurnalnya (Indriani, Riana, dkk, 2016) menyatakan bahwa : "Vuforia merupakan sebuah Software Development Kit (SDK) berbasis AR yang menggunakan layar perangkat mobile sebagai "lensa ajaib" atau kaca untuk melihat kedalam dunia Augmented dimana dunia nyata dan virtual muncul berdampingan. Aplikasi ini membuat preview kamera secara langsung pada layar smartphone untuk mewakili pandangan dari dunia fisik. Objek 3D akan nampak secara langsung di layar smartphone, sehingga akan terlihat objek $3 \mathrm{~d}$ berada didalam dunia nyata".

\subsection{Marker}

Marker adalah pola yang dibuat dalam bentuk gambar yang akan dikenali oleh kamera. Untuk marker standar, pola yang dikenali adalah pola marker dengan bentuk persegi dengan kotak hitam didalamnya. Tetapi saat ini sudah banyak pengembang marker yang membuat tanpa bingkai hitam (Ardhianto, Eka, dkk, 2012).

\subsection{Aksara Minang}

Dalam buku (Nurana, Dkk, 1992) menyatakan bahwa : "Minangkabau biasanya dianggap sebagai negeri dimana tradisi lisannya demikian berkembang sehingga menekan tradisi tulisnya kebelakang. Namun tradisi lisan ternyata bukanlah satu-satunya peninggalan rekaman informasi mengenai kehidupan dan aturan-aturan mengenai kehidupan ada orang minangkabau, diantaranya juga ada yang berbentuk tulisan. Didalam penelitian sejarah membuktikan bahwa di minangkabau juga pernah terdapat semacam aksara. Aksara minangkabau memiliki aksara penyambung komunikasi yang memperkaya kebudayaannya, yaitu pemakaian tulisan arab-minangkabau atau arab-melayu. Disebut dengan nama itu karena huruf-huruf arab telah dikembangkan dengan inovasi lokal agar bisa meliterasikan bahasa oral minangkabau yang pada dasarnya satu puak dalam bahasa melayu".

\subsubsection{Aksara Minang Menurut Zuber Usman}

Menurut Zuber Usman didalam jurnal Herwandi (2008) Aksara minangkabau dikemukakan sebagai berikut :

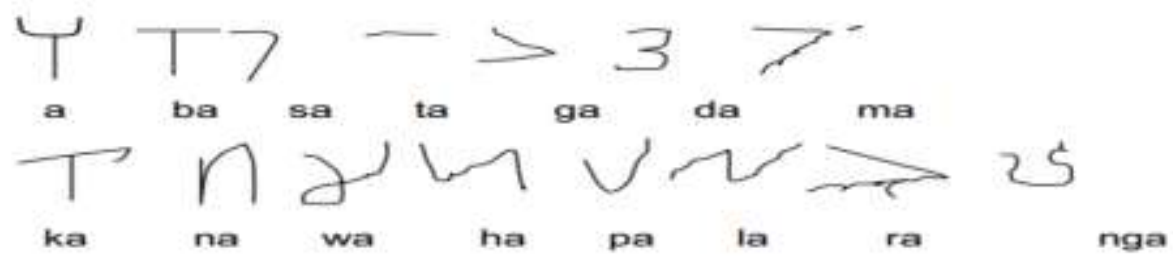

Apabila aksara tersebut diberi tanda tertentu akan dapat dirubah bunyinya: tanda titik $(\bullet \square \square$ di atas mengubah bunyi menjadi berakhiran i ; apabila titik dibawah berubah bunyi berakhiran u ; dan apabila diberi tanda cagak (v) di bawah merubah bunyi menjadi berakhiran $\mathrm{O}$; serta apabila diberi cagak (v) di atas merubah bunyi menjadi e keras. 


\section{Metodologi}

Metodologi penelitian merupakan langkah langkah atau tahapan-tahapan yang dilakukan didalam sebuah penelitian. Berikut merupakan gambar yang berisi konsep kerangka penelitian :

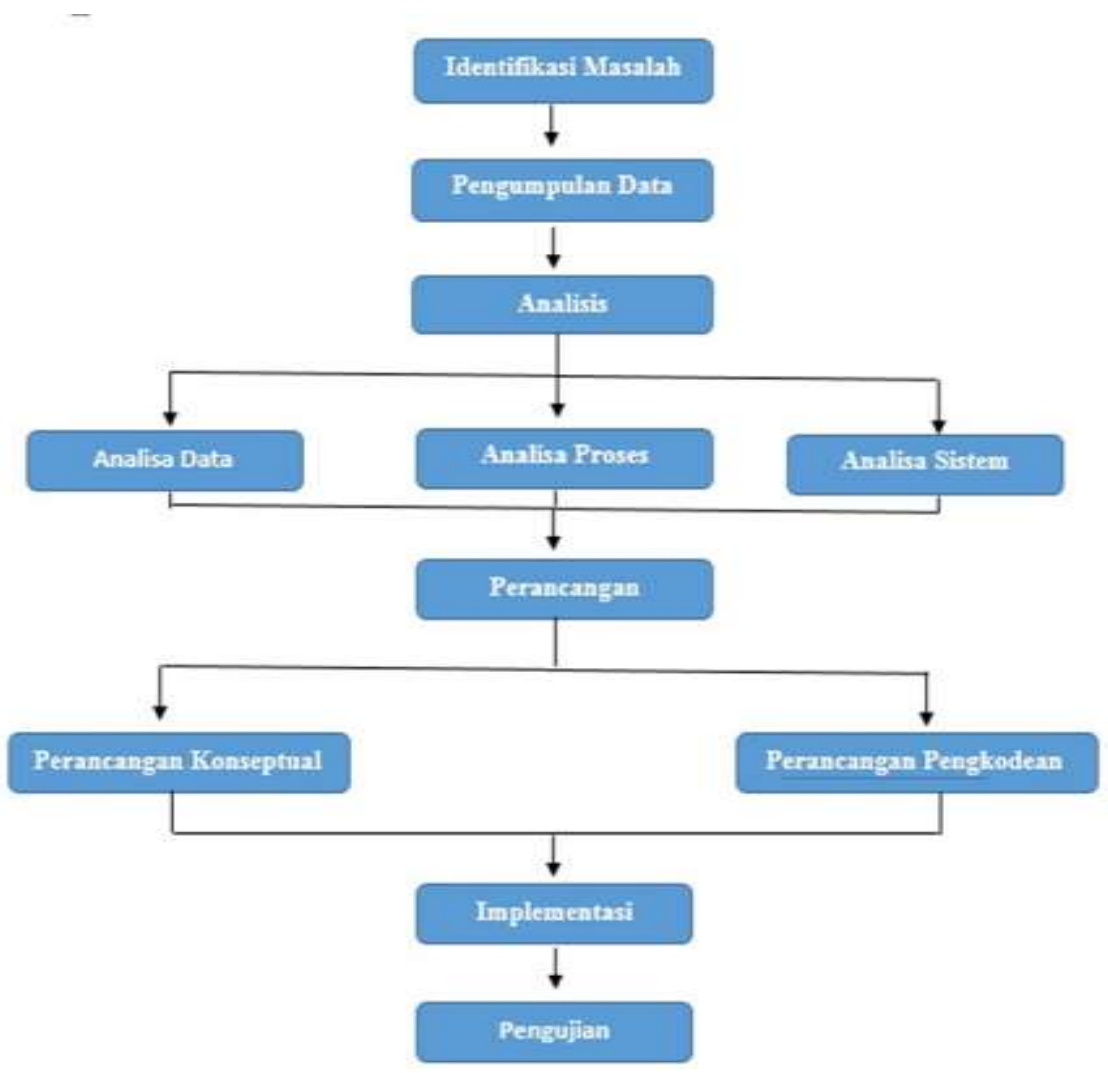

Gambar 1: Kerangka Penelitian

\section{Hasil dan Diskusi}

\subsection{Pengujian Aplikasi}

Pada proses pengujian aplikasi hal pertama yang harus dilakukan adalah instalasi sistem. Instalasi sistem adalah proses dimana aplikasi dipasang pada perangkat keras yaitu smartphone berbasis andriod.

Metode black box yaitu teknik pengujian yang akan menguji fungsionalitas dari fitur-fitur yang disediakan pada aplikasi. Berikut hasil dari pengujian dengan menggunakan metode black box :

Tabel 1 : Hasil Pengujian Aplikasi Augmented Reality Aksara Minang

\begin{tabular}{|l|l|l|l|}
\hline No & Pengujian & Hasil Yang Diharapkan & Hasil Pengujian \\
\hline
\end{tabular}




\begin{tabular}{|c|c|c|c|}
\hline 1 & Instalasi Aplikasi & $\begin{array}{l}\text { Aplikasi terpasang dengan } \\
\text { lancar pada smartphone } \\
\text { android }\end{array}$ & Berhasil \\
\hline 2 & Menjalankan Aplikasi & $\begin{array}{l}\text { Aplikasi berhasil dijalankan } \\
\text { dengan baik }\end{array}$ & Berhasil \\
\hline 3 & Membuka AR kamera & $\begin{array}{l}\text { Aplikasi dapat membuka AR } \\
\text { kamera }\end{array}$ & Berhasil \\
\hline 4 & Mendeteksi Marker & $\begin{array}{l}\text { Aplikasi dapat mendeteksi } \\
\text { marker }\end{array}$ & Berhasil \\
\hline 5 & $\begin{array}{l}\text { Menampilkan } \\
\text { Informasi }\end{array}$ & $\begin{array}{l}\text { Aplikasi dapat menampilkan } \\
\text { informasi aksara minang }\end{array}$ & Berhasil \\
\hline 6 & $\begin{array}{c}\text { Menampilkan } \\
\text { Halaman Tutorial }\end{array}$ & $\begin{array}{l}\text { Aplikasi dapat menampilkan } \\
\text { halaman tutorial dengan } \\
\text { lancar }\end{array}$ & Berhasil \\
\hline 7 & $\begin{array}{c}\text { Membuka Download } \\
\text { Marker }\end{array}$ & $\begin{array}{l}\text { Aplikasi dapat membuka } \\
\text { situs downlad marker }\end{array}$ & Berhasil \\
\hline
\end{tabular}

Pengujian selanjutnya yaitu pengujian pada pencahayaan. Pencahayaann dapat mempengaruhi fungsi dari kamera sehingga apabila pencahayaan baik maka marker dapat lebih cepat terdeteksi sebaliknya apabila pencahayaan gelap marker akan susah terdeteksi. Berikut ini adalah hasil dari pengujian pencahayaan pada aplikasi augmented reality aksara minang :

Tabel 2 : Pengujian Pencahayaan

\begin{tabular}{|c|c|l|}
\hline No & Intensitas Cahaya & \multicolumn{1}{c|}{ Hasil } \\
\hline 1 & Terang & Proses deteksi cepat \\
\hline 2 & Cukup Cahaya & Proses deteksi cepat \\
\hline
\end{tabular}




\begin{tabular}{|c|c|l|}
\hline 3 & Sedikit Cahaya & Proses deteksi sedikit cepat \\
\hline 4 & Gelap & Tidak dapat mendeteksi marker \\
\hline
\end{tabular}

Pada tabel diatas menunjukkan bahwa aplikasi dapat berjalan pada kondisi sedikit cahaya hingga kondisi terang. Untuk hasil yang maksimal diharapkan aplikasi digunakan pada kondisi cukup cahaya dan terang. Namun aplikasi tidak dapat dijalankan pada kondisi gelap sehingga tidak dapat menampilkan marker aksara minang.

\subsection{Pengujian Interface}

Pada tahap pengujian interface dilakukan dengan menggunakan smartphone Redmi Note 5. Aplikasi augmented reality membutuhkan smartphone untuk dapat berjalan dengan baik. Berikut ini merupakan hasil dari pengujian aplikasi augmented reality aksara minang :

1. Tampilan icon pada aplikasi augmented reality aksara minang

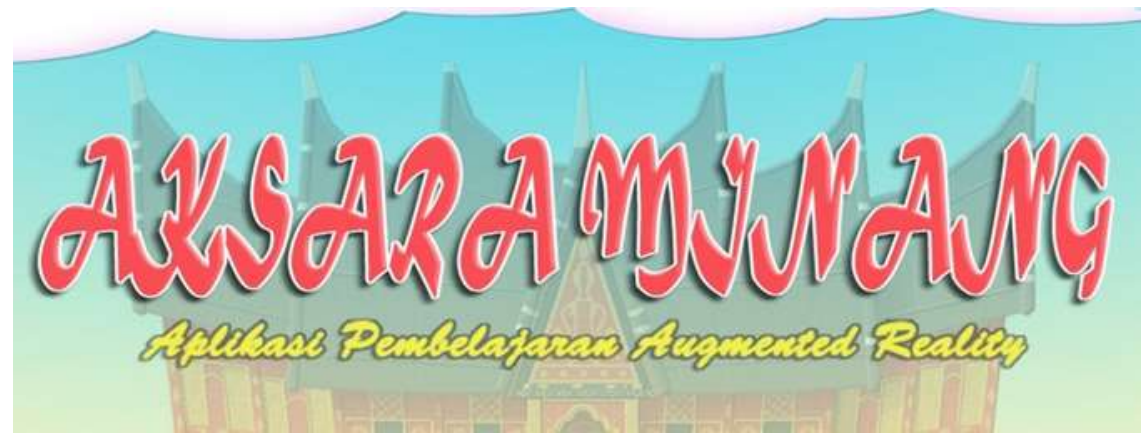

Gambar 2 : Tampilan Icon Aplikasi Augmented Reality Aksara Minang

2. Tampilan splash image ketika aplikasi dijalankan

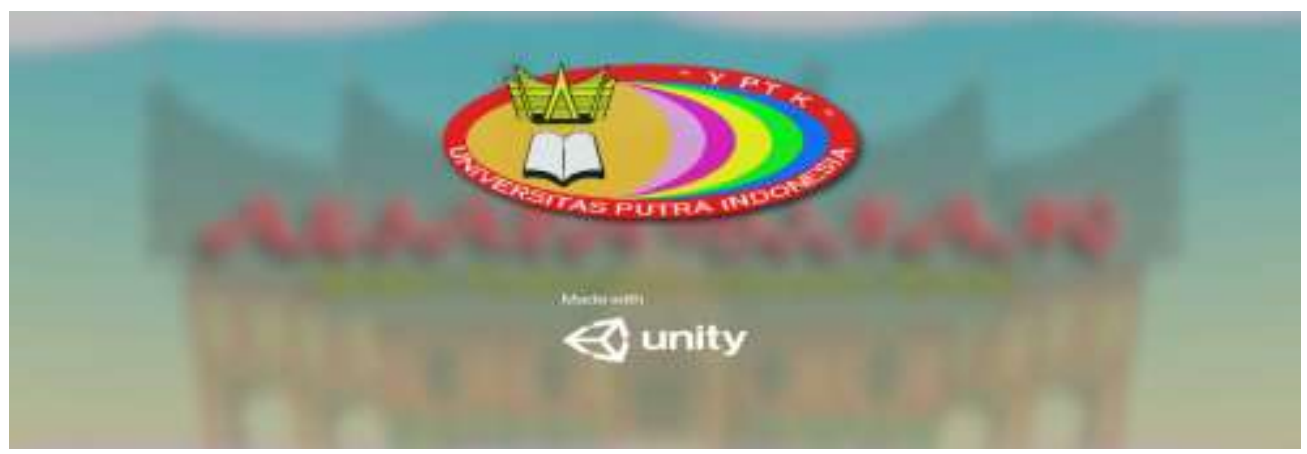

Gambar 3 : Tampilan Splash Image

3. Tampilan loading scene ketika aplikasi akan dimulai 


\section{Gambar 4 : Tampilan Loading Scene}

4. Tampilan menu pada aplikasi augmented reality aksara minang

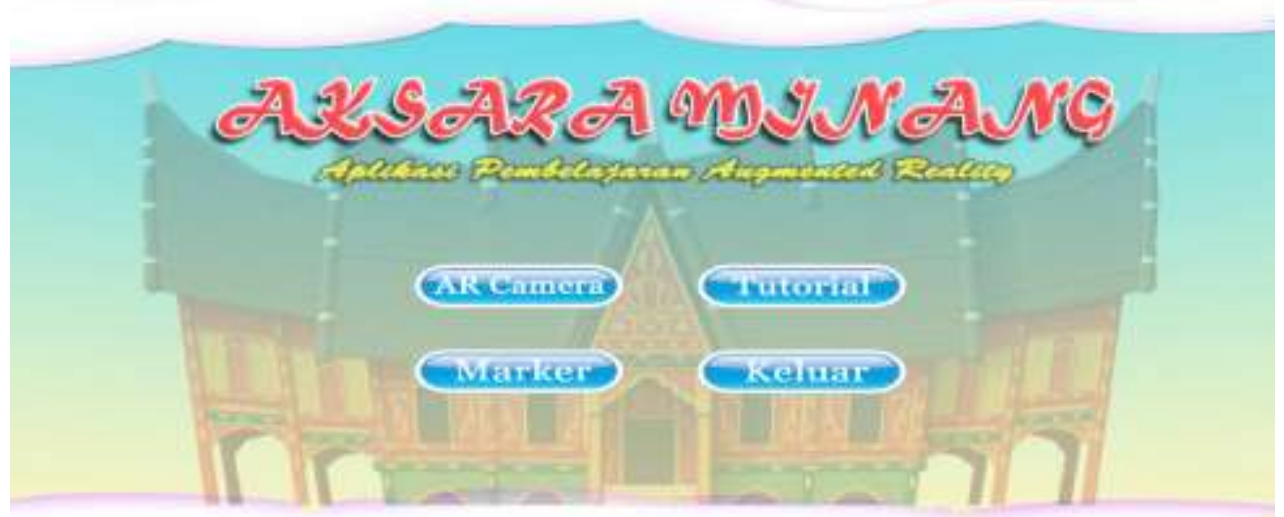

Gambar 5 : Tampilan Menu Aplikasi Augmented Reality Aksara Minang

5. Tampilan AR Camera ketika dipilih akan menampilkan proses augmented reality yang bekerja

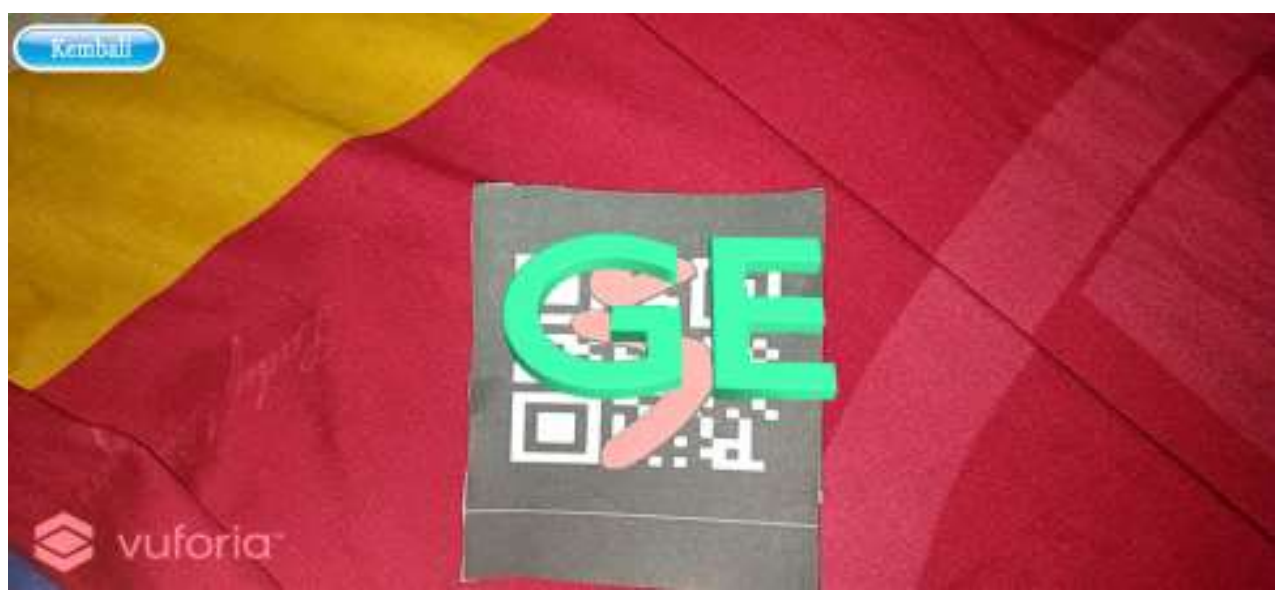

Gambar 6 : Tampilan Proses Augmented Reality Bekerja

6. Tampilan tutorial terdapat tata cara penggunaan aplikasi augmented reality

\section{Kembaii}

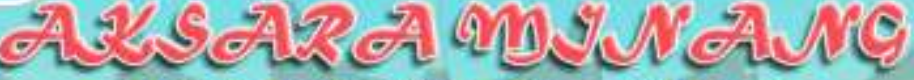

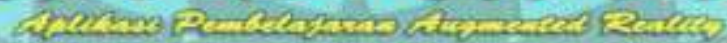

1) Download marker di menu "Marker"

2) Tekan tombol "AR Camera"

3) Arahkan kamera smartphone pada marker 4) Informasi aksara minang akan muncul 


\section{Gambar 7 : Tampilan Tutorial Pada Aplikasi Augmented Reality}

\section{Kesimpulan}

Setelah melakukan penelitian berdasarkan dari bab - bab sebelum nya maka didapati kesimpulan sebagai berikut :

1. Dengan menggunakan aplikasi augmented reality aksara minang dapat mengenalkan informasi yang tepat mengenai aksara minang pada siswa/i maupun guru.

2. Dengan menggunakan aplikasi augmented reality aksara minang dapat mempermudah siswai/i maupun guru mempelajari setiap kata dari aksara minang.

3. Dengan menggunakan aplikasi augmented reality ini diharapkan dapat menambah pengetahuan mengenai aksara minang dan melestarikan aksara minang sehingga tetap diketahui oleh banyak orang.

4. Dengan menggunakan aplikasi augmented reality aksara minang diharapkan dapat menjadi media pembelajaran yang baru untuk siswa/i dalam mempelajari aksara minang.

5. Dengan menggunakan aplikasi augmented reality aksara minang diharapkan dapat menarik minat belajar siswa dalam mempelajari aksara minang

\subsection{Keterbatasan Sistem}

Pada pembuatan augmented reality aksara minang terdapat keterbatasan sistem yang dimiliki oleh aplikasi, berikut adalah keterbatasan sistem pada aplikasi augmented reality aksara minang :

1. Pembacaan marker pada aplikasi augmented reality tergantung pencahayaan dan kualitas kamera.

2. Pada augmented reality tidak dapat menampilkan lebih dari empat marker sehingga tidak dapat merangkai marker sesuai kata - kata.

3. Penyesuaian interface pada setiap smartphone yang digunakan untuk menjalankan aplikasi augmented reality aksara minang.

\subsection{Saran}


Aplikasi augmented reality ini membutuhkan beberapa pengembangan agar dapat menjadi lebih baik. Berikut ini beberapa pengembangan untuk aplikasi augmented reality aksara minang kedepannya :

1. Aplikasi ini dapat dikembangkan pada sistem operasi lain seperti IOS.

2. Aplikasi augmented reality dapat dijalankan pada semua jenis smartphone

3. Penambahan fitur mengenai pembelajaran aksara minang di aplikasi augmented reality seperti tampilan informasi keseluruhan tentang aksara minang.

4. Aplikasi augmented reality dapat mendeteksi marker lebih dari empat agar dapat merangkai kata - kata sesuai marker yang ditampilkan

5. Penambahan kosakata baru untuk aplikasi augmented reality aksara minang sehingga kosa kata dapat diperbanyak dalam aplikasi tersebut.

\section{Referensi}

[1] Apriyani, Meyti Eka, Miftakhul Huda, and Sandi Prasetyaningsih. "Analisis Penggunaan Marker Tracking Pada Augmented Reality Huruf Hijaiyah." Jurnal Infotel 8.1 (2016): 71 77.

[2] Ardhianto, Eka, Wiwien Hadikurniawati, and Edy Winarno. "Augmented Reality Objek 3 Dimensi dengan Perangkat Artoolkit dan Blender." Dinamik-Jurnal Teknologi Informasi 17.2 (2012).

[3] Budi Arifitama, 2017, "Panduan Mudah Membuat Augmented Reality", Hal 1, Yogyakarta, Penerbit ANDI.

[4] Herwandi, Herwandi. "DARI MEGALIT BOROBONO KE TAMBO RUEH BUKU: PENELUSURAN AWAL TENTANG TULISAN MINANGKABAU." Linguistika Kultura 1.3 (2008).

[5] Indriani, Riana, Bayu Sugiarto, and Agus Purwanto. "PEMBUATAN AUGMENTED REALITY TENTANG PENGENALAN HEWAN UNTUK ANAK USIA DINI BERBASIS ANDROID MENGGUNAKAN METODE IMAGE TRACKING VUFORIA." SEMNASTEKNOMEDIA ONLINE 4.1 (2016): 4-7.

[6] Janner, Simarmata. 2010. Rekayasa Perangkat Lunak . Yogyakarta : Penerbit Andi

[7] Lengkong, Hendra N., Alicia AE Sinsuw, and Arie SM Lumenta. "Perancangan Penunjuk Rute Pada Kendaraan Pribadi Menggunakan Aplikasi Mobile GIS Berbasis Android Yang Terintegrasi Pada Google Maps." Jurnal Teknik Elektro dan Komputer 4.2 (2015): 18-25.

[8] Nurana, Syamsidar, dan Zulyani Hidayah. 1992. Undang Undang Adat Minangkabau. Departemen Pendidikan dan Kebudayaan

[9] Prihandoyo, M. Teguh. "Unified Modeling Language (UML) Model Untuk Pengembangan Sistem Informasi Akademik Berbasis Web." Jurnal Informatika: Jurnal Pengembangan IT 3.1 (2018): 126-129.

[10] Sigit, Haris Triono, and Sulistiyono Sulistiyono. "Desain Aplikasi Pembelajaran Bahasa Jawa Banten pada Perangkat Mobile Berbasis Android Menggunakan Teknologi Web Service." Prosiding Seminar Nasional Riset Terapan| SENASSET. 2017. 
[11] S, Rosa A. \& Shalahudin, M. 2013. Modul Pembelajaran Rekayasa Perangkat Lunak. Bandung : Informatika

[12] Wardani, Setia. "Pemanfaatan Teknologi Augmented Reality (AR) untuk Pengenalan Aksara Jawa pada Anak." Jurnal Teknologi 8.2 (2015): 104-111. 